\title{
Frequency and Characteristics of Interval Colorectal Cancer in Actual Clinical Practice: A KASID Multicenter Study
}

\author{
Kyeong OK Kim ${ }^{1}$, Kyu Chan Huh ${ }^{2}$, Sung Pil Hong ${ }^{3}$, Won Hee Kim${ }^{4}$, Hyuk Yoon ${ }^{5}$, Sang Wook Kim ${ }^{6}$, Yeon Soo Kim \\ Jong Ha Park ${ }^{8}$, Jun Lee ${ }^{9}$, Bum Jae Lee ${ }^{10}$, and Young Sook Park ${ }^{11}$ \\ ${ }^{1}$ Division of Gastroenterology and Hepatology, Department of Internal Medicine, Yeungnam University College of Medicine, Daegu, \\ ${ }^{2}$ Department of Internal Medicine, Konyang University College of Medicine, Daejeon, ${ }^{3}$ Department of Internal Medicine, Yonsei University \\ College of Medicine, Seoul, ${ }^{4}$ Department of Internal Medicine, CHA Bundang Medical Center, CHA University School of Medicine, ${ }^{5}$ Department \\ of Internal Medicine, Seoul National University Bundang Hospital, Seongnam, ${ }^{6}$ Department of Internal Medicine, Chonbuk National University \\ Medical School, Jeonju, ${ }^{7}$ Department of Internal Medicine, Hallym University College of Medicine, Chuncheon, ${ }^{8}$ Department of Internal \\ Medicine, Inje University Haeundae Paik Hospital, Busan, ${ }^{9}$ Department of Internal Medicine, Chosun University College of Medicine, Gwangju, \\ ${ }^{10}$ Department of Internal Medicine, Korea University College of Medicine, and ${ }^{11}$ Department of Internal Medicine, Eulji Hospital, Eulji University \\ College of Medicine, Seoul, Korea
}

Background/Aims: The aims of the present study were to determine the frequency of interval colorectal cancers (CRCs) after surveillance colonoscopy and to compare the clinicopathologic features and survival outcomes with those of noninterval CRCs. Methods: From January 2003 to December $2013,66,016$ follow-up colonoscopies for 38,412 patients performed within recommended time were reviewed retrospectively based on data from 11 tertiary hospitals in South Korea. To compare clinicopathologic features and survival rates for interval CRC, 106 patients with non-interval CRC matched in age and gender were included. Results: Among the 66,016 colonoscopies performed within the surveillance period, 63 cases $(63 / 66,016)$ of interval CRC were detected, and 53 were finally included in the analysis. The mean age was $69.9 \pm 8.8$ years, and the male to female ratio was 1.94:1. Although the occurrence rate of cancer in the right side colon was higher than that of non-interval CRC, interval CRCs were predominantly left sided. Other clinicopathologic features and overall survival were not significantly different between the two groups. Missed lesion was suspected to be the most common cause (29 cases, 54.7\%). Conclusions: The frequency of interval CRC among patients who had undergone a surveillance colonoscopy was $0.095 \%$. While sharing some similar clinical features and survival outcomes, interval CRCs in Korea developed more often in males and on the left side in contrast to results from Western studies. (Gut Liver 2018;12:537-543)
Key Words: Interval colorectal neoplasms; Colonoscopy; Surveillance

\section{INTRODUCTION}

Although the incidence of colorectal cancer (CRC) has decreased, it is still the second most common cause of cancerrelated death in United States. ${ }^{1}$ In South Korea, CRC is the third most common cancer, and its increase in incidence is believed to be associated with the adoption of Western diet and the development of improved diagnostic modalities. ${ }^{2}$ Furthermore, the frequency of screening tests under colonoscopy for CRC in South Korea has increased as well. ${ }^{3}$ Colonoscopy is currently considered as the gold standard and the most effective screening method, because it enables the detection and removal of precancerous lesions at the same time. ${ }^{4,5}$ However, a number of authors have recently cast doubt on the effectiveness of colonoscopies in reducing the incidence of proximal colon cancer and CRC-related mortality. ${ }^{6-8}$ Since a significant proportion of colorectal neoplasia is missed during colonoscopic examinations, CRC-related mortality decrease only by $37 \%$ to $65 \% .6,9,10$ Furthermore, 5\% to 8\% of CRC cases were diagnosed within the recommended surveillance window after the prior colonoscopy. ${ }^{8,11}$ CRCs, diagnosed relatively soon after negative index colonoscopy, are referred to as interval CRCs, which have been lately recognized as an important clinical issue. ${ }^{11}$ To reduce the risk of interval CRC, a comprehensive understanding and the

Correspondence to: Kyu Chan Huh

Department of Internal Medicine, Konyang University College of Medicine, 158 Gwanjeodong-ro, Seo-gu, Daejeon 35365, Korea

Tel: +82-42-600-9370, Fax: +82-42-600-9091, E-mail: kchuh2020@hanmail.net

Received on October 31, 2017. Revised on January 16, 2018. Accepted on March 3, 2018. Published online August 9 , 2018

pISSN 1976-2283 eISSN 2005-1212 https://doi.org/10.5009/gnl17485

@) This is an Open Access article distributed under the terms of the Creative Commons Attribution Non-Commercial License (http://creativecommons.org/licenses/by-nc/4.0) which permits unrestricted non-commercial use, distribution, and reproduction in any medium, provided the original work is properly cited. 
improvement of surveillance strategies are indispensable. Several attempts have been made to address these issues, but the majority of the previous studies performed were conducted on CRC patients from specific populations. Thus, the overestimation and limitation in terms of determining the incidence and characteristics of interval CRC have been resulted. ${ }^{12-17}$ In fact, a number of endoscopists have concerned about the incidence of unpredicted CRC soon after their index colonoscopy during the period of surveillance for each patient.

Accordingly, this study was undertaken to assess the frequency of interval CRC in real clinical aspects. In addition, the comparison of the clinicopathologic features and clinical outcomes between interval CRC and non-interval CRC patients, age- and sex-matched, was covered in this study.

\section{MATERIALS AND METHODS}

This is a nation-wide study of intestinal tumor research group, Korean Association for the Study of Intestinal Diseases (KASID). The data, collected by members of KASID from 11 tertiary hospitals, included 66,016 cases of follow-up colonoscopy conducted within 5 years after index colonoscopy or 3 years after endoscopic removal of high-risk adenomas, were reviewed retrospectively. Patients who met the following criteria were included: (1) age >50 years (2) complete colonoscopic examination up to the cecum during follow-up. All index colonoscopic findings included either negative results or polyps that would be removed thereafter. Patients, each of whose cecum was not reached under index colonoscopy, were included. The exclusion criteria were: (1) a history of colectomy for CRC or inflammatory bowel disease or familial adenomatous polyposis; and (2) a history of CRC at index colonoscopy or incomplete histologic information. From January 2003 to December 2013, 38,412 patients received follow-up colonoscopy within 5 years after index colonoscopy or 3 years after resection of high-risk adenoma. The followings were scrutinized in the analysis: the patients' features, bowel preparation status at index colonoscopy, the presence of adenoma, treatment, and the characteristics of lesions in several aspects such as morphology, etiology and staging. To compare clinicopathologic features and survival outcome, 106 age- and gender-matched patients with a history of non-interval CRC during the same study period (from January 2003 to December 2013) were also included.

\section{Definition}

In this study, interval CRC was defined as colorectal adenocarcinoma developed within 5 years of index colonoscopy or 3 years after endoscopic removal of preexisting high-risk adenoma; advanced adenoma or the number of lesions $\geq 3$. ${ }^{18}$ Index colonoscopy was defined as the colonoscopy performed before the diagnostic colonoscopy of CRC. Non-interval CRC was defined as CRC which was not included in the criteria of interval
CRC. The frequency of interval CRC was illustrated as follows:

$$
\text { Frequency }=\frac{\text { Total cases of interval colorectal cancer }}{\text { Total numbers of follow-up colonoscopies }}
$$

A right side colon cancer was defined as CRC located proximal to splenic flexure. Bowel preparation status was assessed using the Aronchick bowel preparation scale; the adequacy of bowel preparation was classified into three categories: excellent, good and fair. ${ }^{19}$ And advanced adenoma includes tubular adenoma with diameter $>10 \mathrm{~mm}$, villous or tubulovillous adenoma, any adenoma with high-grade dysplasia or intramucosal adenocarcinoma. High-risk adenoma included advanced adenoma or three or more adenoma.

To determine causes of interval CRC, each case was sorted into three groups: missed lesion, incomplete removal, and newly developed cancer. Missed lesions at index colonoscopy were defined as cancers detected at different locations from those of prior lesions that were diagnosed within 30 months after index colonoscopy, or after 30 months characterized by having all advanced features of CRC such as $2 \mathrm{~cm}$ or larger and advanced stage (III and IV). ${ }^{16}$ Incomplete resection indicated cancers detected at the same site of previous polypectomy. ${ }^{16}$ Newly developed cancers were defined as cancers detected at least 30 months after index colonoscopy with only one feature of advanced cancer. ${ }^{16}$

\section{Statistical analysis}

To compare the clinical features and survival outcome of the interval CRC group with the non-interval CRC group, the McNemar chi-square test and Fisher exact test for categorical variables and the Independent Sample t-test for continuous variables were utilized. p-values $<0.05$ were indicated statistically significant. Overall survivals in the two study groups were compared by Kaplan-Meier survival analysis and the log-rank test. The statistical analysis was rendered using IBM Statistics SPSS version 20.0 (IBM Corp., Armonk, NY, USA). This study was approved by the Institutional Review Boards of Yeungnam University Hospital (IRB No. 2014-01-427) and those of the remaining 10 participating hospitals. Informed consent was obtained from each patient.

\section{RESULTS}

\section{Baseline characteristics of the study subjects}

The 38,412 patients underwent 66,016 cases of follow-up colonoscopy within 5 years of negative index colonoscopy or 3 years after removal of high-risk adenoma. During the surveillance period, 88 CRC cases, including 25 intramucosal cancers, were diagnosed. During the study period, 63 cases of interval CRC were detected, but 10 of these cases, follow-up loss or transfer to other hospital cases for various reasons after the 
diagnosis of CRCs were noted. We could not know their final pathologic outcomes. Therefore, we excluded these patients from the analysis. Eventually, 53 cases of interval CRC (interval CRC group) were included in the analysis of clinicopathological feature (Fig. 1).

For the 159 study subjects with interval and non-interval CRC, mean age was $69.9 \pm 8.8$ years, the male to female ratio was 1.94:1. Mean number of follow-up colonoscopy per patient over the study period was 1.73 , and median time from index colonoscopy to first follow-up study was 28 months (range, 6 to 94 months).

The interval CRC group had a non-significantly higher rate of underlying chronic disease (e.g., hypertension or diabetes) than the non-interval CRC group (75.5\% vs 58.5\%; $\mathrm{p}=0.057$ ). Twenty-four patients (45.3\%) in the interval CRC group were smokers and $21(19.8 \%)$ in the non-interval CRC group were smokers and $62.3 \%$ had an alcohol history, and both of these differences were significant ( $p=0.003, p=0.004$, respectively) (Table 1).

\section{Features of index colonoscopy in patients with interval CRC}

Twenty-six patients (49.1\% of interval CRC patients) were examined by faculty members who were professors at university hospitals with at least 5 years of experiences after fellowship course in gastrointestinal endoscopy; 24 (45.3\%) by trainees with experience of less than a year; $3(5.6 \%)$ by trainees with experience of more than a year. Bowel preparation was adequate for 45 (84.9\%) of index colonoscopies. A diverticulum was noted in two cases (3.7\%) only. An adenoma was noted in 34 (64.2\%), and the mean number of adenomas per patient was 2.61. Of these 34 patients, 13 (24.5\%) were advanced adenomas and 11 of the $13(84.6 \%)$ were removed by endoscopy using techniques, such as, endoscopic mucosal resection or endoscopic submucosal dissection (Table 2).

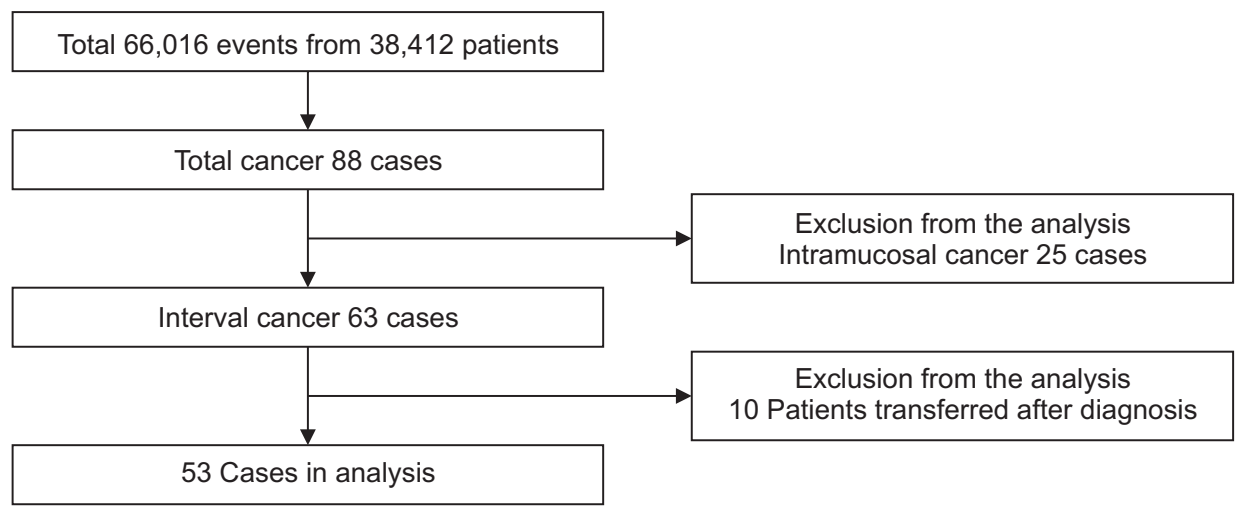

Fig. 1. Study flow chart.

Table 1. Baseline Characteristics of Patients with Interval or NonInterval CRC

\begin{tabular}{lccc}
\hline \multicolumn{1}{c}{ Variable } & $\begin{array}{c}\text { Interval CRC } \\
(\mathrm{n}=53)\end{array}$ & $\begin{array}{c}\text { Non-interval CRC } \\
(\mathrm{n}=106)\end{array}$ & $\mathrm{p}$-value \\
\hline Age, yr & $69.6 \pm 8.8$ & $71.1 \pm 9.1$ & 0.461 \\
Sex, male:female & $1.94: 1$ & $1.94: 1$ & 1 \\
Underlying disease & $40(75.5)$ & $62(58.5)$ & 0.057 \\
$\quad$ Hypertension & $22(42.0)$ & $48(45.3)$ & 0.126 \\
Diabetes & $10(18.9)$ & $12(11.3)$ & 0.455 \\
Others* & $8(15.1)$ & $6(5.7)$ & 0.321 \\
Smoking history & $24(45.3)$ & $21(19.8)$ & 0.003 \\
Alcohol history & $30(62.3)$ & $33(31.1)$ & 0.004 \\
Mean no. of events ${ }^{\dagger}$ & 1.73 & - & - \\
\hline
\end{tabular}

Data are presented as mean \pm SD or number $(\%)$.

CRC, colorectal cancer.

*Others, chronic kidney disease (3 vs 2), chronic liver disease (2 vs 1), cerebrovascular disease ( 2 vs 2 ), arrhythmia ( 1 vs 1 ); ${ }^{\dagger}$ An event is defined as a follow-up colonoscopy within 5 years of an index colonoscopy.
Table 2. Clinical Features of Index Colonoscopy

\begin{tabular}{lc}
\hline \multicolumn{1}{c}{ Variable } & Value \\
\hline Examiner & $26(49.1)$ \\
Faculty & $3(5.9) / 24(45.3)$ \\
Trainee, $<1$ yr/ $\geq 1$ yr of experience & \\
Bowel preparation status & $20(37.7) / 17(32.1) / 8(15.1)$ \\
Excellent/good/fair & $8(15.1)$ \\
Poor (or inadequate) & $2(3.7)$ \\
Presence of diverticulum & $34(64.2)$ \\
Presence of adenoma & $2.61 \pm 2.42$ \\
No. of adenoma (per patients) & $13(24.5)$ \\
Presence of advanced adenoma & \\
Treatment of advanced adenoma & $11(84.6)$ \\
EMR/ESD & $2(15.4)$ \\
Cold biopsy &
\end{tabular}

Data are presented as number (\%) or mean \pm SD.

EMR, endoscopic mucosal resection; ESD, endoscopic submucosal dissection. 


\section{Clinical features, causes, and clinical outcomes of inter- val CRC}

Interval CRC were diagnosed at a mean 31.7 \pm 21.5 months after index colonoscopy and they were most commonly found in the ascending colon (15 cases, 28.3\%), followed by the sigmoid and rectum (13 cases, 24.5\%), which showed its predominance of left side (right vs left, $41.6 \%$ vs 58.4\%) (Table 3).

In contrast, the rectum was favored by non-interval CRC, and the sigmoid colon ranked second. Although the proportion of right side cancer was higher than non-interval CRC, both interval and non-interval CRCs occurred more commonly in the left than in the right side colon and there was no significant difference in the distribution ( $\mathrm{p}=0.078$ ).

Mean lesion sizes of the interval and non-interval CRC groups were $35.6 \pm 22.7 \mathrm{~mm}$ and $40.7 \pm 37.50 \mathrm{~mm}$, respectively $(\mathrm{p}=0.365)$. In both groups, the fungating type and moderate differentiation were the most common morphologic and differentiation types, respectively, and cancers usually invaded or penetrated the subserosal layer (Table 3). Colectomy was performed in 31 patients (58.5\%) in the interval CRC group and in 50 patients (47.2\%) in

Table 3. Comparison of the Clinicopathologic Features of Interval and Non-Interval CRC

\begin{tabular}{|c|c|c|c|}
\hline Variable & $\begin{array}{c}\text { Interval CRC } \\
(n=53)\end{array}$ & $\begin{array}{l}\text { Non-interval } \\
\text { CRC }(n=106)\end{array}$ & p-value \\
\hline $\begin{array}{l}\text { Time interval from } \\
\text { index colonoscopy, mo }\end{array}$ & $31.7 \pm 21.5$ & - & \\
\hline Mean CEA & $40.9 \pm 20.0$ & $96.2 \pm 62.1$ & 0.244 \\
\hline Distribution, right:left & $22: 31$ & 29:76 & 0.078 \\
\hline Cecum & $3(5.67)$ & $4(3.77)$ & 0.687 \\
\hline Ascending colon & $15(28.3)$ & 19 (17.9) & 0.153 \\
\hline Transverse colon & $4(7.55)$ & $6(5.66)$ & 0.732 \\
\hline Descending colon & $5(9.43)$ & 0 & 0.004 \\
\hline Sigmoid colon & 13 (24.53) & 35 (33.0) & 0.360 \\
\hline Rectum & $13(24.53)$ & 42 (39.6) & 0.077 \\
\hline \multicolumn{4}{|l|}{ Morphology } \\
\hline Fungating & $26(49.1)$ & 57 (53.8) & 1.000 \\
\hline Polypoid & $10(18.9)$ & 19 (17.9) & 0.404 \\
\hline $\begin{array}{l}\text { Flat (including } \\
\text { constricting) }\end{array}$ & $9(17.0)$ & 20 (18.9) & 1.000 \\
\hline Sessile & $8(15.1)$ & $9(8.50)$ & 0.608 \\
\hline Size, mm & $35.6 \pm 22.7$ & $40.9 \pm 37.5$ & 0.365 \\
\hline \multicolumn{4}{|l|}{ Differentiation } \\
\hline Well & $15(28.3)$ & $18(17.0)$ & 0.146 \\
\hline Moderate & $36(67.9)$ & 74 (69.8) & 0.855 \\
\hline Poorly & $1(1.89)$ & $12(11.3)$ & 0.061 \\
\hline Signet ring cell & $1(1.89)$ & $2(1.89)$ & 1.000 \\
\hline
\end{tabular}

Data are presented as mean \pm SD or number $(\%)$.

CRC, colorectal cancer; CEA, carcinoembryonic antigen. the non-interval CRC group. Endoscopic removal by standard polypectomy, endoscopic mucosal resection, or endoscopic submucosal dissection was performed in 15 (28.3\%) and 33 (31.1\%) patients in the interval and non-interval CRC groups, respectively, but no significant intergroup difference was found for treatment modality. In both groups, stage I was the most common and stage III was the second most common; no significant intergroup difference was observed for cancer staging (Table 4). During 60 months of follow-up duration, median survival was not reached by either group, and the log-rank test showed no significant difference of survival in the two groups (Fig. 2). All these clinical features and outcomes were not different significantly after adjusting the gender, smoking, alcohol and comorbidities. There was no significant risk factor of interval CRC by multivariate analysis.

To list in the order, the most common cause of interval CRC was missed lesion (29 cases, 54.7\%) followed by remnant lesion

Table 4. Clinical Outcomes of Interval and Non-Interval CRC

\begin{tabular}{lrcc}
\hline \multicolumn{1}{c}{ Variable } & $\begin{array}{c}\text { Interval CRC } \\
(\mathrm{n}=53)\end{array}$ & $\begin{array}{c}\text { Non-interval } \\
\text { CRC }(\mathrm{n}=106)\end{array}$ & $\mathrm{p}$-value \\
\hline 1st line treatment & & & \\
Endoscopic treatment* & $15(28.3)$ & $33(31.1)$ & 1.000 \\
Colectomy & $31(58.5)$ & $50(47.2)$ & 0.160 \\
Chemotherapy & $1(1.89)$ & $5(4.7)$ & 0.606 \\
Supportive care & $6(11.3)$ & $18(17.0)$ & 0.094 \\
Stage & & & \\
I & $23(43.4)$ & $39(36.8)$ & 0.491 \\
II & $7(13.2)$ & $10(9.4)$ & 0.587 \\
III & $16(30.2)$ & $39(36.8)$ & 0.481 \\
IV & $7(13.2)$ & $18(17.0)$ & 0.647 \\
\hline
\end{tabular}

Data are presented as number (\%).

CRC, colorectal cancer.

*ESD (Endoscopic submucosal dissection), EMR (Endoscopic submucosal Resection).

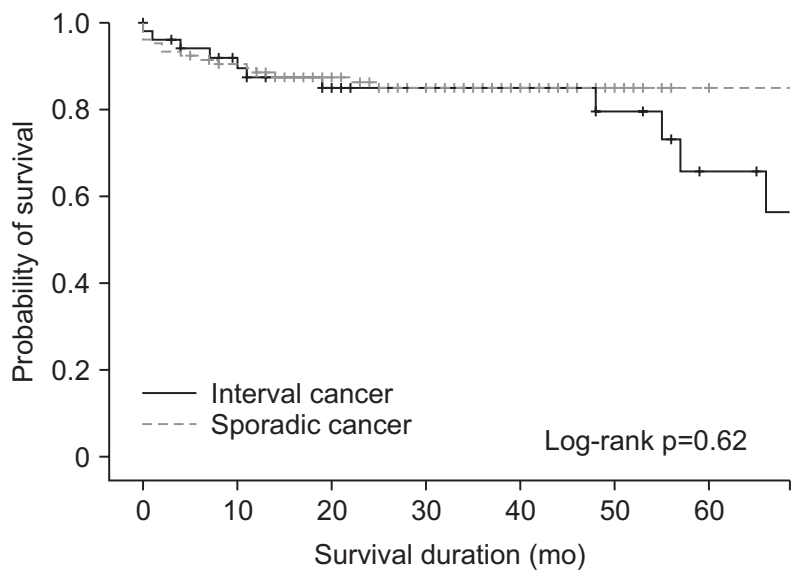

Fig. 2. Kaplan-Meier survivals of patients with interval colorectal cancer (CRC) and non-interval CRC. 
after previous endoscopic resection (13 cases, 24.5\%) and newly developed cancer (11 cases, 20.8\%) (Fig. 3).

\section{DISCUSSION}

Although colonoscopy followed by polypectomy decreases the risk of CRC and mortality, cancers may develop within short time period after negative index colonoscopy. ${ }^{20}$ In the present study, interval CRC was detected in 63 patients (9.5 per 10,000 cases of surveillance), at a mean $31.7 \pm 21.5$ months after index colonoscopy, out of the 66,016 cases of follow-up colonoscopy $(38,412$ patients) conducted within recommended of surveillance period.

The majority of previous studies on this topic have assessed the rate of interval CRC among all CRCs, and the figures ranged from $2 \%$ to $9 \% \%^{6,8,21}$ However, this provides little information about the incidence of interval CRC. For this reason, our study was designed to evaluate how often interval cancers could be detected by follow-up colonoscopy in clinical practice. We found that the rate of interval CRC detection during the surveillance period was at $0.09 \%$ and another recent Korean data also reported $0.2 \%$ of CRC after negative colonoscopy. ${ }^{22}$ It might have led to the frequency of interval CRC from many follow-up studies in such individuals is relatively lower than our expectation.

The previous Western studies on interval CRC have indicated that female ${ }^{23,24}$ and the presence of a comorbidity are risk factors. ${ }^{23}$ According to one nation-wide study, interval CRC tends to be associated with comorbidities, an advanced age, and females. ${ }^{25}$ However, the present study showed that interval CRC was associated more often with males. In some part, this difference might have been due to gender imbalances in the study populations since male patients in Korea underwent colonoscopy more frequently for screening and/or surveillance. Actually, in our study, the frequency of follow-up colonoscopy in male patients was nearly twice as numerous as that of female patients. Other previous Korean studies also reported that interval CRCs developed more predominantly in males than females (ratio of 188:92 in Lee et al. ${ }^{22}$, 19:9 in Kim et al. ${ }^{26}$ ) although

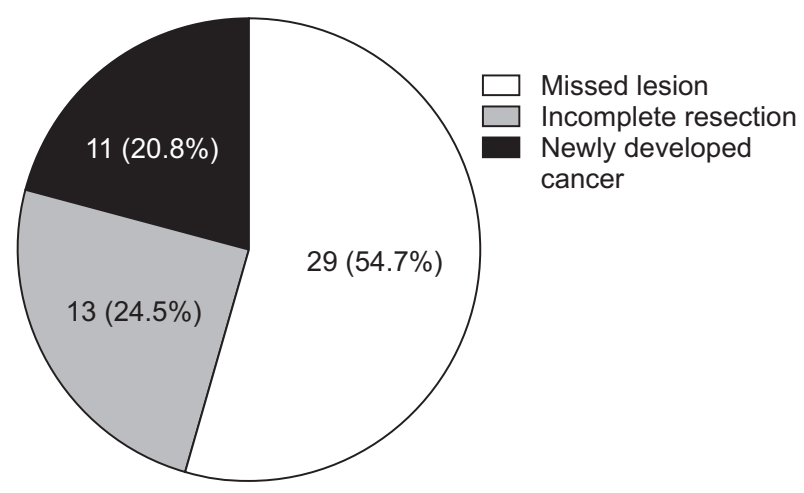

Fig. 3. Suspected causes of interval colorectal cancer. such results were yet to be found statistically insignificant. The same results were reported in other Asian groups with fewer patients. Japanese group reported that 13 cases of interval CRCs diagnosed within 3 years after initial colonoscopy were male predominance (ratio of 8:5) ${ }^{27}$ and 14 cases of interval CRCs after polypectomy in Chinese study also showed male prevalence (ratio of $11: 3)^{28}$

In this study, although the proportion of right side colon was higher than non-interval CRC, interval CRC was observed more in the left side colon than in the right side colon. A nationwide population based study in Korea showed the similar results (61.9\% in distal colon). ${ }^{22}$ Another Korean single center study also reported that 16 cases from 28 interval CRCs were in left side colon (57.1\%). ${ }^{26}$ Japanese group also reported that eight cases from 13 interval CRCs were located in rectum and sigmoid colon $^{27}$ and the trend was also shown in Chinese study with 3:11 of proximal to distal ratio. ${ }^{28}$

Although we could not explain the exact mechanism, these Asian group results suggested that the possibility of ethnic differences in the gender and tumor location of interval CRCs. One Korean research which compared the difference of Sessile serrated adenoma/polyp (SSA/P) between Koreans and Americans claimed evidence of ethnic difference in location, gender proportion and molecular subtype. ${ }^{29}$ This study showed that SSA/Ps without dysplasia tended to develop more often in females (63\% vs 37\%) in American, whereas SSA/Ps with or without dysplasia, develop in males more than about three-fourths in Korean. Additionally, SSA/Ps with dysplasia, precancerous lesion, were more frequently located in left side colon in Koreans (58.3\% vs 41.7\%). In addition, BRAF mutations and hMLH1 methylation were less frequent in Koreans, compared to Americans. Because these factors have been suggested as the etiologies of interval CRC, there might be the possibilities of ethnic differences in development of interval CRC. ${ }^{29}$ Although our study could not get the exact information about serrated lesion due to old case inclusion, there might be the possibility of association in our results.

Incompetence in colonoscopy has been known as an obvious cause of interval CRC. Although total number of endoscopic exam done by faculty members in Korea far outweighed that of the trainee, the frequency of interval CRCs between faculty members and trainees were similar (49.1\% vs $45.3 \%$ ) in our study. Considering the phenomenon, in Korea, index colonoscopy performed by trainee raised the possibility of development of interval CRC.

Other risk factors, such as, diverticulosis, ${ }^{30}$ a history of polypectomy, ${ }^{8}$ examination by a non-gastroenterologist without an endoscopic specialty, ${ }^{8,23,24,30}$ and a lower adenoma detection rate had also been suggested. ${ }^{18}$ We could not assess these risk factors precisely, but 34 (64.2\%) of the interval CRC patients in our study had adenomas and 13 (24.5\%) had advanced adenoma in index colonoscopies. Unfortunately, we were not able to assess the association between diverticulum and the risk of interval 
CRC because we could not determine the exact number of patients with diverticulum due to the retrospective nature of the study.

Suggested in Farrar et al. ${ }^{11}$ as well, this study showed a tendency that the lesions of interval CRC were smaller than those of non-interval CRC, yet no significance was found. Another study proposed that interval CRCs, usually small and flat, can be easily missed. ${ }^{31}$

Our results showed similar serum CEA levels, stages, and survivals in the two study groups, which was in line with several previous studies, ${ }^{11,24}$ In one previous comparative study of interval CRC and non-interval CRC, it was suggested that the similarities shown by interval and non-interval CRC indicated that missed lesions were an important cause of interval CRC as these similarities indicate interval CRC did not have an aggressive biology. ${ }^{11}$

The most common suspected etiology in our study was a missed lesion and this accounted for 23 cases (43.3\%), and the second most common was incomplete resection of adenoma at index colonoscopy. Other studies on interval CRC have produced similar results, and from 54\% to 65\% cases were found to be associated with a missed lesion or incomplete removal. 5,16,28,32 However, these two etiologies could be adequately corrected by improving the quality of colonoscopic examinations. Referring to previous several studies, interval CRC has been associated with quality indicators, such as, adenoma detection rate, completeness of endoscopic examinations, bowel preparation status, and clear resection of adenoma. ${ }^{20,33,34}$ To prevent missing critical lesions, endoscopists should perform careful inspections, especially of the right side colon, for flat, depressed, or serrated lesions and resect polyps vigorously to ensure complete removal. ${ }^{35}$ Furthermore, endoscopists should try to increase adenoma detection rates, by inspecting for at least 6 minutes and by attending educational programs. The status of bowel preparation is also important. In fact, in one Korean tandem colonoscopy study, it was found that poor bowel preparation significantly increased colon polyp, adenoma, and advanced adenoma miss rates. ${ }^{36}$

Several molecular profile studies have shown that microsatellite instability, ${ }^{37} \mathrm{CpG}$ island methylator phenotype, ${ }^{38}$ and lower KRAS mutation rate ${ }^{39}$ are associated with interval CRC development. However, the retrospective nature of this study excluded the necessity of these molecular factors, because some of interval CRCs were diagnosed when these examinations were unavailable.

The present study was obviously limited by its retrospective nature of design, which introduced the possibility of missing interval CRC cases and limited our assessment of some risk factors, such as family history, diverticulosis, and molecular profiles. In addition, because of the multicenter nature of the study, data heterogeneity is an issue. Nonetheless, the present study also has its merits. In particular: (1) it provides, for the first time, the frequency of interval CRC development as detected by follow-up colonoscopy during actual clinical practice;
(2) Although our data was from those of the tertiary hospital, it was conducted on a non-discriminative nation-wide basis and included a large number of patients that underwent colonoscopy; and (3) it features the comparison of interval CRC and noninterval CRC that had been rarely covered in the previous Asian studies.

In conclusion, the frequency and prevalence of interval CRC were $0.095 \%(63 / 66,016)$ and $0.16 \%(63 / 38,412)$ respectively in this study. Interval CRC was more prevalent in males, the proportion of right side colon location was higher than those of non-interval cancer, however, more often detected in the left side colon. The size tended to be smaller compared to non-interval CRC and no significant difference in survival outcome was observed between interval and non-interval CRC groups until 60 months after diagnosis. However, we need a longer duration of follow-up to confirm the results and to clarify differences between our results and those of the West regarding the clinical features or outcomes of interval CRC, particularly the biological aspects. Noted that since the most commonly suspected causes are correctable, the incidence of interval CRC can be reduced by putting efforts to improve the quality of colonoscopy through close inspection and complete resection of neoplastic lesions.

\section{CONFLICTS OF INTEREST}

No potential conflict of interest relevant to this article was reported.

\section{ACKNOWLEDGEMENTS}

This study was supported by the National Research Foundation of Korea Granted funded by the Korea Government (NRF2017R1A2B2006514).

\section{REFERENCES}

1. Jemal A, Siegel R, Xu J, Ward E. Cancer statistics, 2010. CA Cancer J Clin 2010;60:277-300.

2. Jung KW, Park S, Kong HJ, et al. Cancer statistics in Korea: incidence, mortality and survival in 2006-2007. J Korean Med Sci 2010;25:1113-1121.

3. Cha JM. Colonoscopy quality is the answer for the emerging issue of interval cancer. Intest Res 2014;12:110-116.

4. Winawer SJ, Zauber AG, Ho MN, et al. Prevention of colorectal cancer by colonoscopic polypectomy. The National Polyp Study Workgroup. N Engl J Med 1993;329:1977-1981.

5. Pohl H, Robertson DJ. Colorectal cancers detected after colonoscopy frequently result from missed lesions. Clin Gastroenterol Hepatol 2010;8:858-864.

6. Baxter NN, Goldwasser MA, Paszat LF, Saskin R, Urbach DR, Rabeneck L. Association of colonoscopy and death from colorectal cancer. Ann Intern Med 2009;150:1-8. 
7. Brenner H, Chang-Claude J, Seiler CM, Rickert A, Hoffmeister M. Protection from colorectal cancer after colonoscopy: a populationbased, case-control study. Ann Intern Med 2011;154:22-30.

8. Singh H, Nugent Z, Demers AA, Bernstein CN. Rate and predictors of early/missed colorectal cancers after colonoscopy in Manitoba: a population-based study. Am J Gastroenterol 2010;105:2588-2596.

9. Kahi CJ, Imperiale TF, Juliar BE, Rex DK. Effect of screening colonoscopy on colorectal cancer incidence and mortality. Clin Gastroenterol Hepatol 2009;7:770-775.

10. Zauber AG, Winawer SJ, O'Brien MJ, et al. Colonoscopic polypectomy and long-term prevention of colorectal-cancer deaths. N Engl J Med 2012;366:687-696.

11. Farrar WD, Sawhney MS, Nelson DB, Lederle FA, Bond JH. Colorectal cancers found after a complete colonoscopy. Clin Gastroenterol Hepatol 2006;4:1259-1264.

12. Avidan B, Sonnenberg A, Schnell TG, Leya J, Metz A, Sontag SJ. New occurrence and recurrence of neoplasms within 5 years of a screening colonoscopy. Am J Gastroenterol 2002;97:1524-1529.

13. Gorski TF, Rosen L, Riether R, Stasik J, Khubchandani I. Colorectal cancer after surveillance colonoscopy: false-negative examination or fast growth? Dis Colon Rectum 1999;42:877-880.

14. Haseman JH, Lemmel GT, Rahmani EY, Rex DK. Failure of colonoscopy to detect colorectal cancer: evaluation of 47 cases in 20 hospitals. Gastrointest Endosc 1997;45:451-455.

15. Nozaki R, Takagi K, Takano M, Miyata M. Clinical investigation of colorectal cancer detected by follow-up colonoscopy after endoscopic polypectomy. Dis Colon Rectum 1997;40(10 Suppl):S16-S22.

16. Pabby A, Schoen RE, Weissfeld JL, et al. Analysis of colorectal cancer occurrence during surveillance colonoscopy in the dietary Polyp Prevention Trial. Gastrointest Endosc 2005;61:385-391.

17. Shehadeh I, Rebala S, Kumar R, Markert RJ, Barde C, Gopalswamy N. Retrospective analysis of missed advanced adenomas on surveillance colonoscopy. Am J Gastroenterol 2002;97:1143-1147.

18. Kaminski MF, Regula J, Kraszewska E, et al. Quality indicators for colonoscopy and the risk of interval cancer. N Engl J Med 2010;362:1795-1803.

19. Aronchick CA, Lipshutz WH, Wright SH, Dufrayne F, Bergman G. A novel tableted purgative for colonoscopic preparation: efficacy and safety comparisons with Colyte and Fleet Phospho-Soda. Gastrointest Endosc 2000;52:346-352.

20. Robertson DJ, Greenberg ER, Beach M, et al. Colorectal cancer in patients under close colonoscopic surveillance. Gastroenterology 2005;129:34-41.

21. Bressler B, Paszat LF, Chen Z, Rothwell DM, Vinden C, Rabeneck L. Rates of new or missed colorectal cancers after colonoscopy and their risk factors: a population-based analysis. Gastroenterology 2007;132:96-102.

22. Lee CK, Choi KS, Eun CS, et al. Risk and characteristics of postcolonoscopy interval colorectal cancer after a positive fecal test: a nationwide population-based study in Korea. Cancer Res Treat 2018;50:50-59.

23. Baxter NN, Sutradhar R, Forbes SS, Paszat LF, Saskin R, Rabeneck
L. Analysis of administrative data finds endoscopist quality measures associated with postcolonoscopy colorectal cancer. Gastroenterology 2011;140:65-72.

24. Brenner H, Chang-Claude J, Seiler CM, Hoffmeister M. Interval cancers after negative colonoscopy: population-based case-control study. Gut 2012;61:1576-1582.

25. Erichsen R, Baron JA, Stoffel EM, Laurberg S, Sandler RS, Sørensen HT. Characteristics and survival of interval and sporadic colorectal cancer patients: a nationwide population-based cohort study. Am J Gastroenterol 2013;108:1332-1340.

26. Kim CJ, Jung YS, Park JH, et al. Prevalence, clinicopathologic characteristics, and predictors of interval colorectal cancers in Korean population. Intest Res 2013;11:178-183.

27. Matsuda T, Fujii T, Sano Y, et al. Five-year incidence of advanced neoplasia after initial colonoscopy in Japan: a multicenter retrospective cohort study. Jpn J Clin Oncol 2009;39:435-442.

28. Huang Y, Gong W, Su B, Zhi F, Liu S, Jiang B. Risk and cause of interval colorectal cancer after colonoscopic polypectomy. Digestion 2012;86:148-154.

29. Kim KM, Lee EJ, Ha S, et al. Molecular features of colorectal hyperplastic polyps and sessile serrated adenoma/polyps from Korea. Am J Surg Pathol 2011;35:1274-1286.

30. Cooper GS, Xu F, Barnholtz Sloan JS, Schluchter MD, Koroukian SM. Prevalence and predictors of interval colorectal cancers in medicare beneficiaries. Cancer 2012;118:3044-3052.

31. Heresbach D, Barrioz T, Lapalus MG, et al. Miss rate for colorectal neoplastic polyps: a prospective multicenter study of back-to-back video colonoscopies. Endoscopy 2008;40:284-290.

32. Patel SG, Ahnen DJ. Prevention of interval colorectal cancers: what every clinician needs to know. Clin Gastroenterol Hepatol 2014;12:7-15.

33. Lieberman DA, Weiss DG, Harford WV, et al. Five-year colon surveillance after screening colonoscopy. Gastroenterology 2007;133:1077-1085.

34. Pohl H, Srivastava A, Bensen SP, et al. Incomplete polyp resection during colonoscopy-results of the complete adenoma resection (CARE) study. Gastroenterology 2013;144:74-80.e1.

35. Lasisi F, Rex DK. Improving protection against proximal colon cancer by colonoscopy. Expert Rev Gastroenterol Hepatol 2011;5:745-754.

36. Hong SN, Sung IK, Kim JH, et al. The effect of the bowel preparation status on the risk of missing polyp and adenoma during screening colonoscopy: a tandem colonoscopic study. Clin Endosc 2012;45:404-411.

37. Sawhney MS, Farrar WD, Gudiseva S, et al. Microsatellite instability in interval colon cancers. Gastroenterology 2006;131:1700-1705.

38. Arain MA, Sawhney M, Sheikh S, et al. CIMP status of interval colon cancers: another piece to the puzzle. Am J Gastroenterol 2010;105:1189-1195.

39. Shaukat A, Arain M, Anway R, Manaktala S, Pohlman L, Thyagarajan B. Is KRAS mutation associated with interval colorectal cancers? Dig Dis Sci 2012;57:913-917. 